Vol.16, No. 58, January, 2021, 75-84

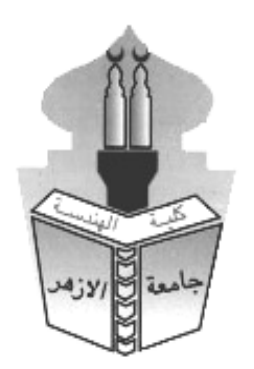

\title{
DEVELOPMENT OF LANDSCAPE ELEMENTS TO ACHIEVE ECONOMIC SUSTAINABILITY
}

\author{
Sherihan Adel Hegazy \\ Department of Architecture,The Higher institute of Engineering, EL Sherouk,Cairo, Egypt. \\ Email: eng_sherihan_adel@yahoo.com.
}

\begin{abstract}
:
Sustainable urban planning depends on making a balance between the environment, the economy and the social needs. So it can afford the functionality and the good quality of life for the residence or the users of the planning zones, as these zones could be new or need to be rehabilitated or developed under the scope of sustainability. The priority of these planning is to fulfill the needs of the society and his objectives within the environmental systems and the economic aspects. The liability issue concerns the absence of the aspects of managing the landscape realm in a successful manner under the scope of the economic sustainability.The objective is to reach the latest sustainable landscape realm that can be used in any site without making any deterioration; otherwise its usage can affect the efficiency of the site. The methodologies used in the research:

1 st Using the literature review to introduce the main definitions, and the concerned criterions of the economic sustainability to manage the landscape realm of the sites.

2nd the analytical methodology is used to analyze the sustainable landscape realm and compare it with the other aspects of sustainability to reach the efficiency could be achieved within using every realm.
\end{abstract}

\section{KEYWORDS: Development, Landscape, Economic, Sustainability, Urban Planning.}

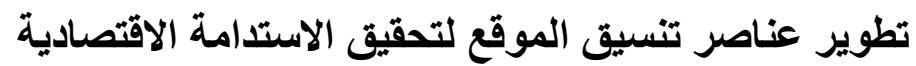

شرم الهنان عادل المعمارية، أكاديمية الشروق، القاهرة، مصر.

Email: eng_sherihan_adel@yahoo.com. البريد الاليكتروني:

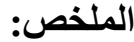

تعمل المخططات العمر انية المستدامة علي إيجاد التوازن بين البيئة و الاقتصاد و القيم الاجتماعية، حتى تلبي احتياجات

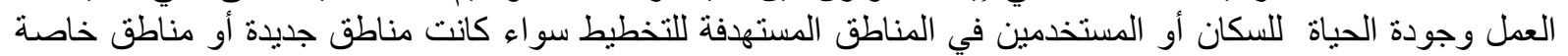

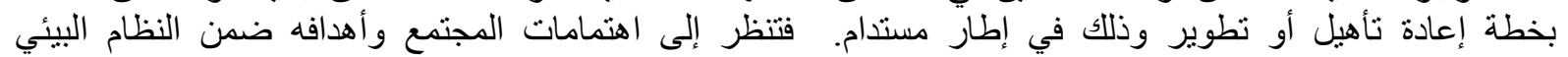

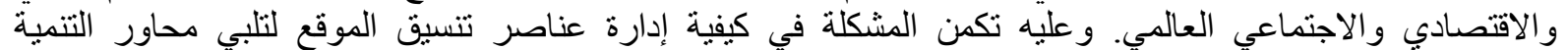

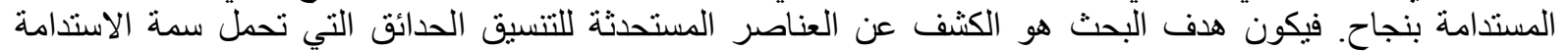

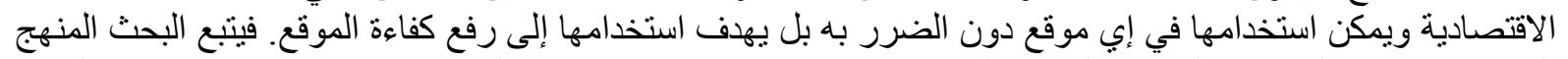

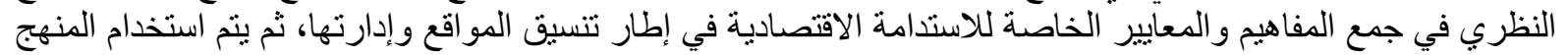

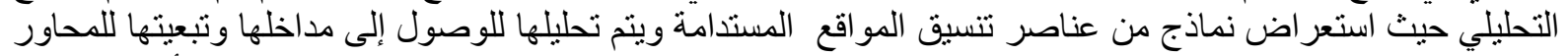

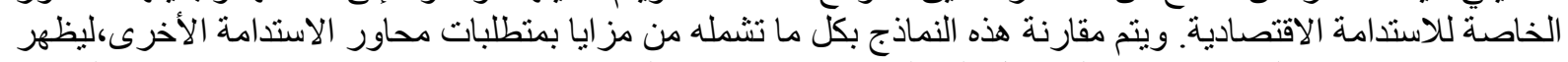

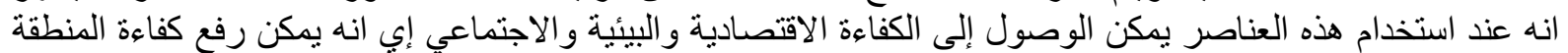

الكلمات المفتاحية : التطوير، تنسيق المواقع، الاقتصاد، الاستدامة، التخطيط العمراني. 


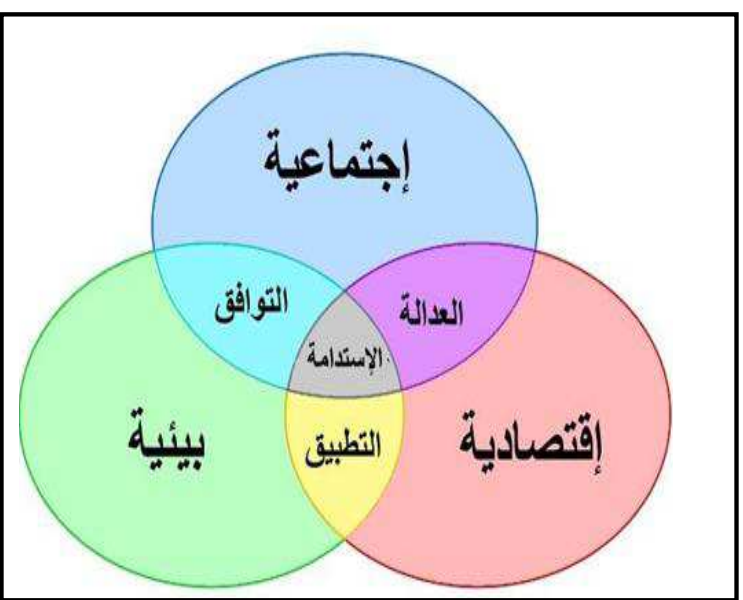

شكل (1) يوضح عناصر الاستدامة ـ المصدر : الباحثة
الاستدامة هي محاولة لتوفير افضل النتائج للانسان و البيئة الطبيعية في

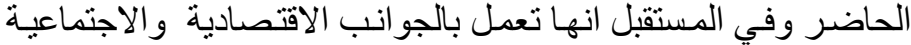

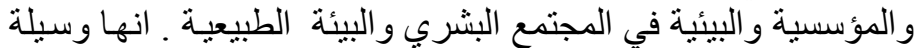

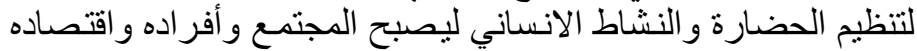

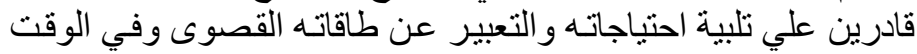

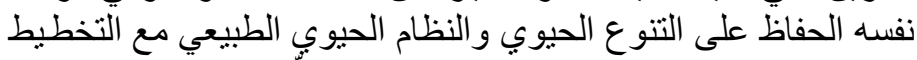

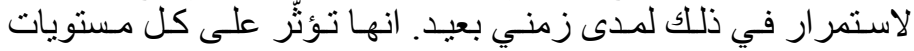

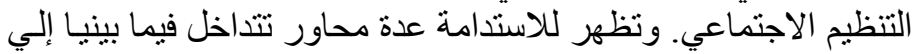

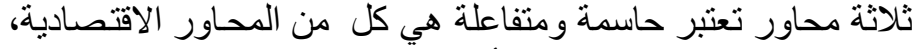

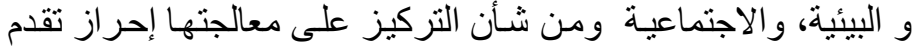

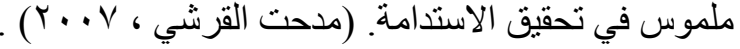

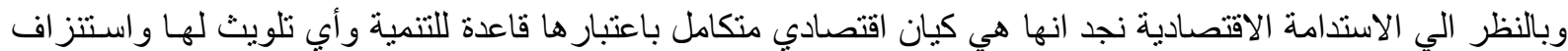

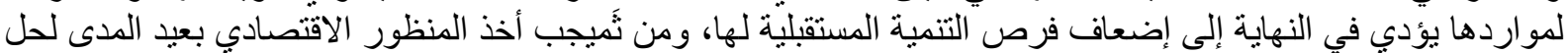

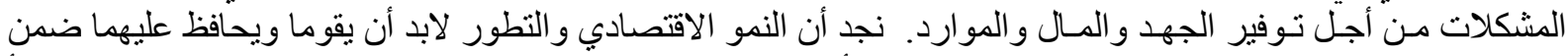

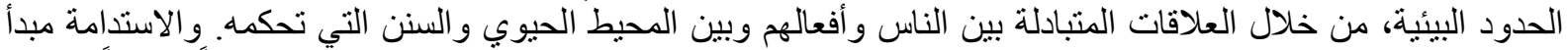

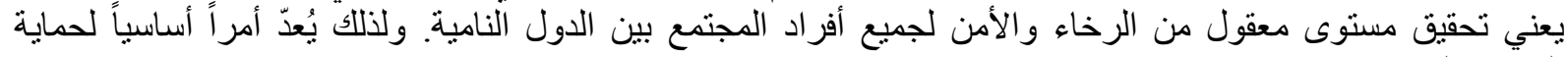

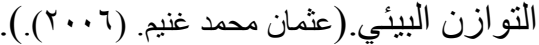

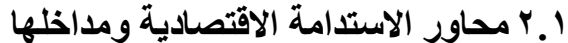

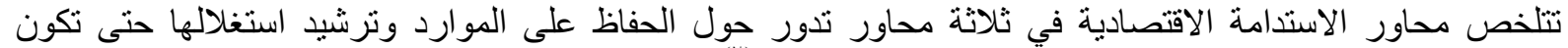

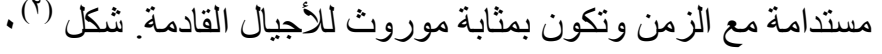

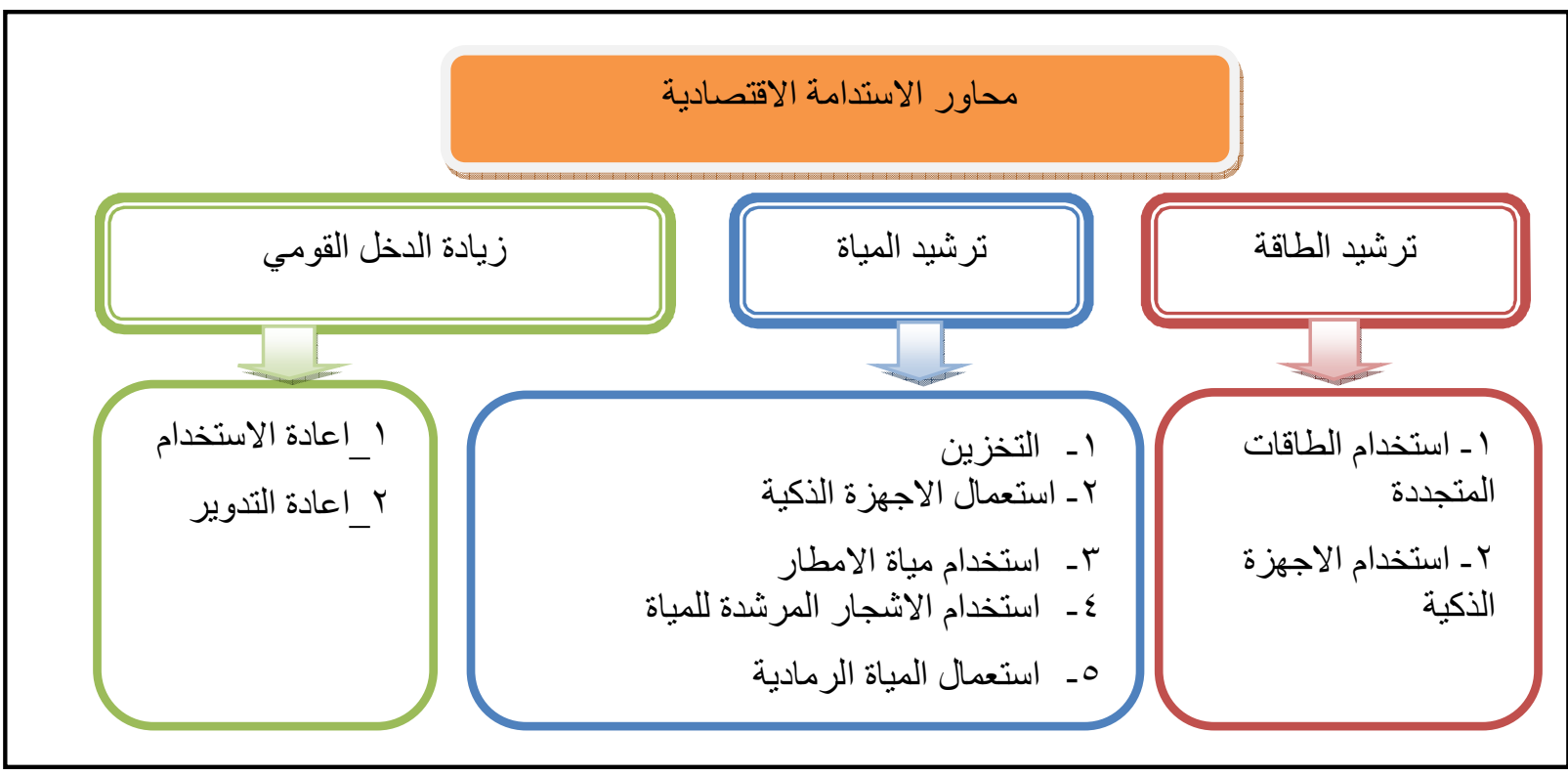

شكل (ץ) يوضح الترابط بين مداخل و محاور الاستدامة الاقتصادية ـ المصدر : الباحثة

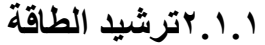

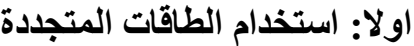
و وعد التعامل مع الطاقاتات المتجددة نجد ان هذه الطاقات منتوعة كالطاقة الثمسية ، طاقة الرياح ،طاقة المياه ، طاقة الحرارة الارضية ، الطاقة الحيوية و الطاقة الحركية. 
أ ـ الطاقة الثمسية Solar energy و يتم استخدام الخلايا الثمسية فيعناصر تنسيق الموقع منل أعمدة الإنارة و النافورات و التماثيل النحنية و مواقف

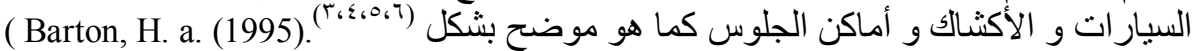

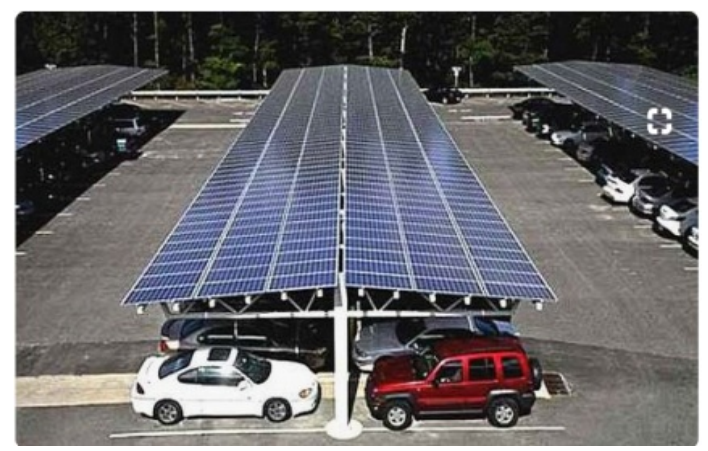

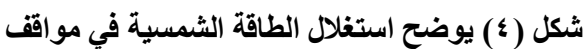
انتظار السيارات لانتاج الطاقة الكهربائية http://solarenergyworld.work

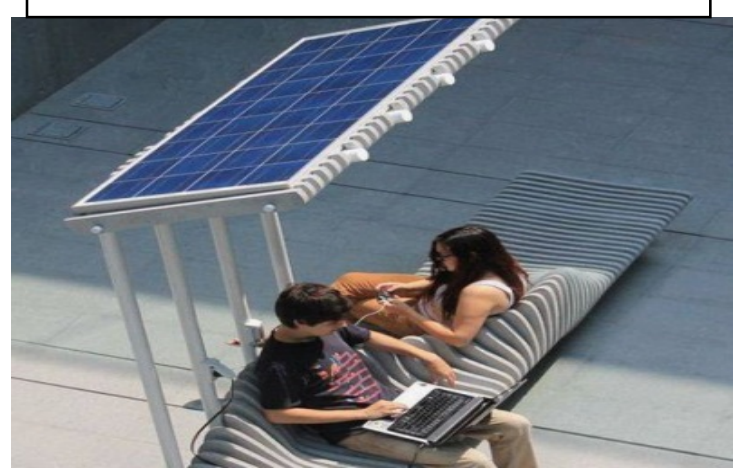

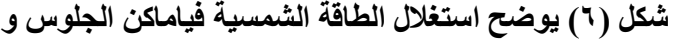
استخراج الكهرباء لثحن اجهزة التليفون و الكبيوتر الثرائر https://i.pinimg.com/originalsolar-power
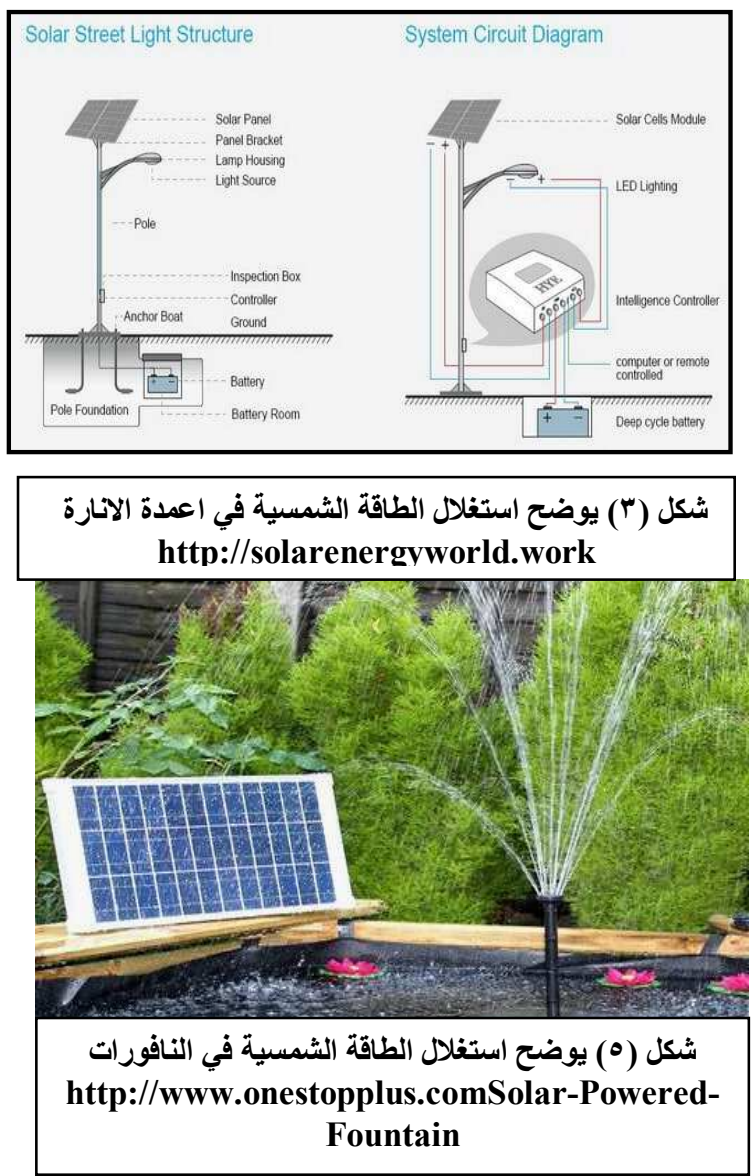

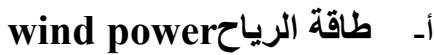

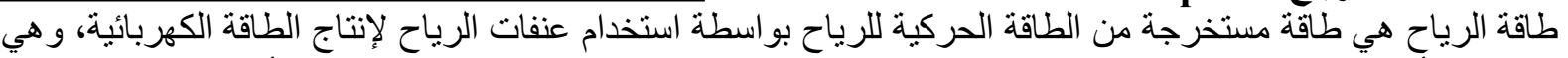

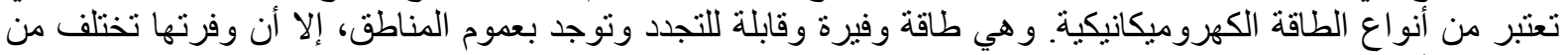

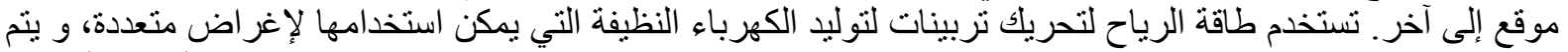

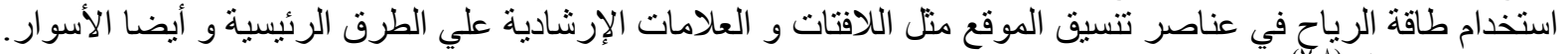

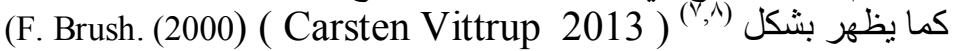

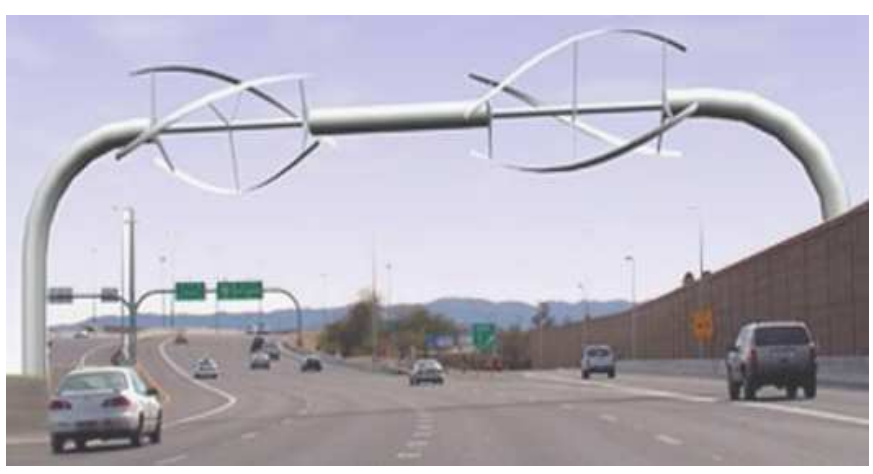

شكل (^) يوضح استغلال طاقة الرياح في العلامات الارشادية http://inhabitat.com/student-designs-highway-power/

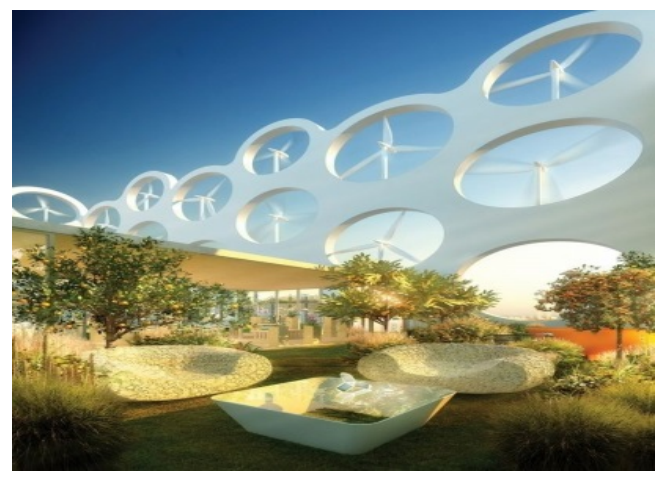

شكل (V) يوضح استغلال طاقة الرياح في الاسوار http://designspiration.net 


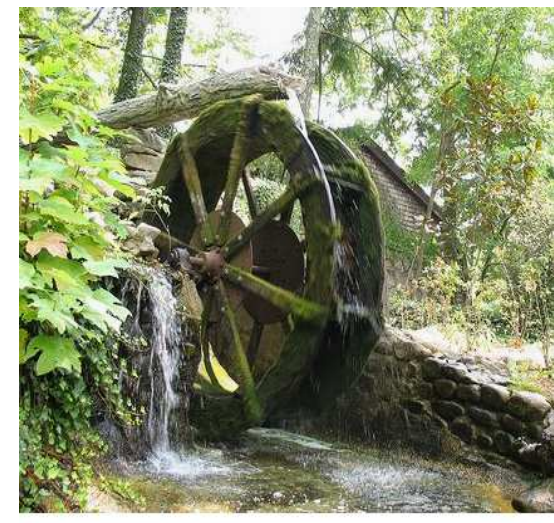

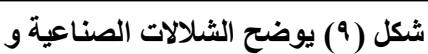

وضعها في ارتفاع عالي في توليا طاقلة المياعة

http://www.motherearthnews.co $\mathrm{m} /$ renewable-energy

تتحول حركة المياه الطبيعية على سطح الأرض إلى طاقة حركة كانت تستخدم

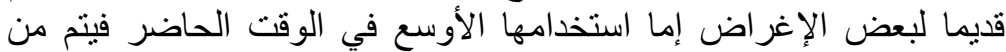

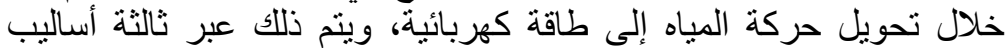

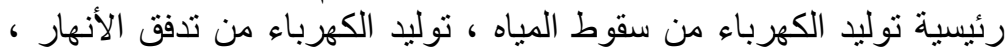

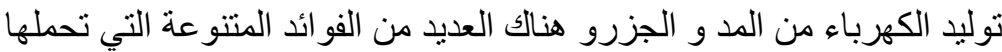

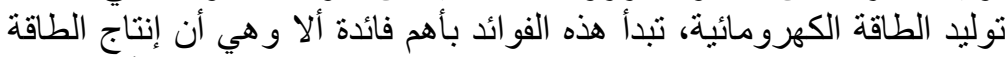

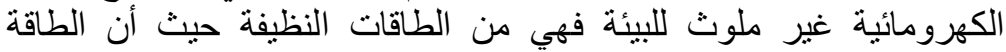

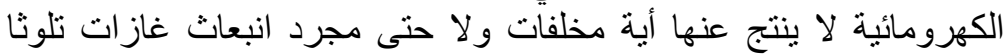

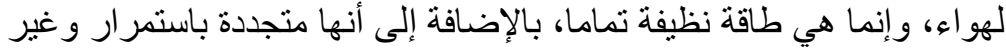
قابلة للنفاذ، كما أن هذه الطاقة توفر تكاليف باهظة يتم إنفاقها على شراء ألى

الوقود المستخدم في توليد الكهرباء، كما أنها في نفس الوقت تحتاج إلى تكلفة إلى الكية

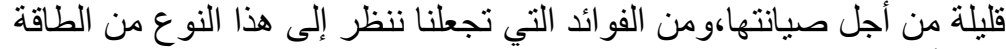

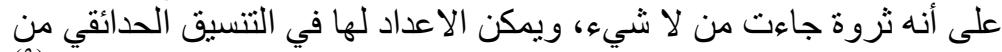

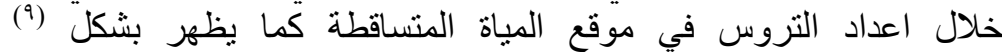

. (kiistian,2011)

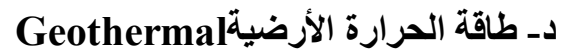

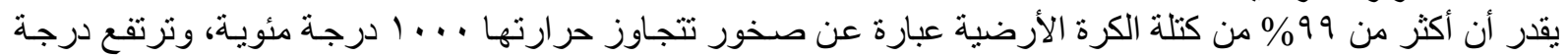

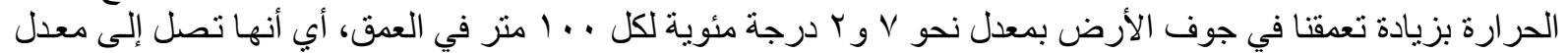

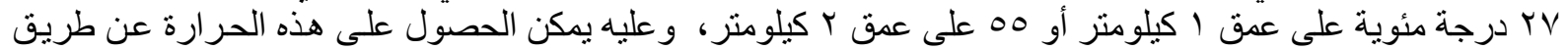

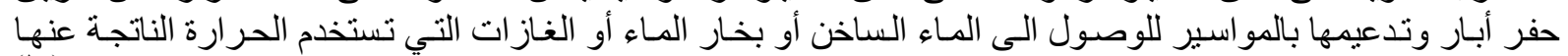

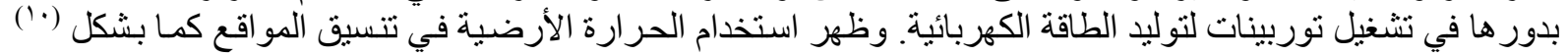

(Johnson, J. R. (1993))
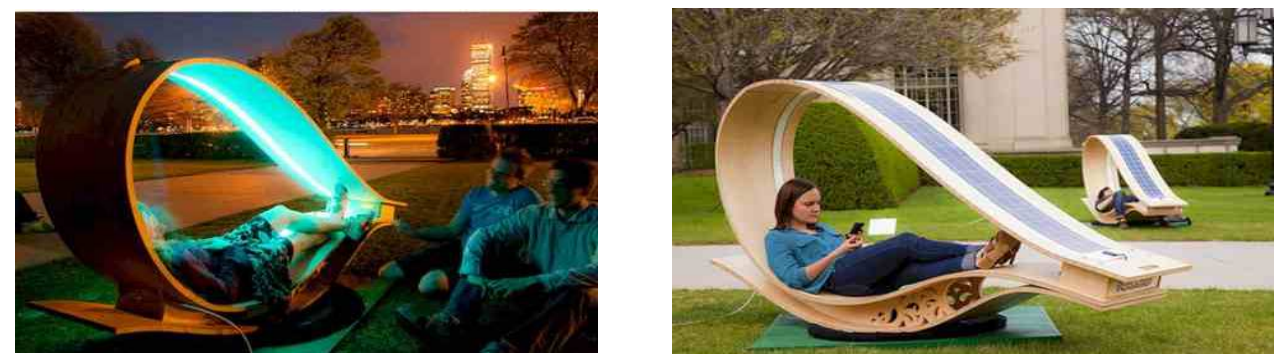

شكل (• ( ) يوضح استغلال الحرارة الارضية في توليد الكهرباء في عناصر الجلوس http://www.motherearthnews.com/renewable-energy

مـ طاقة المواد العضوية Biomass

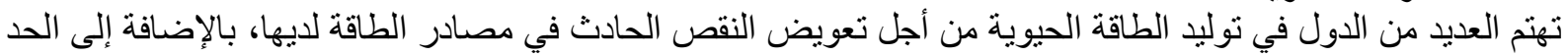

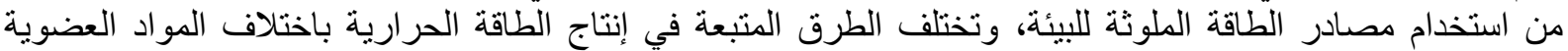

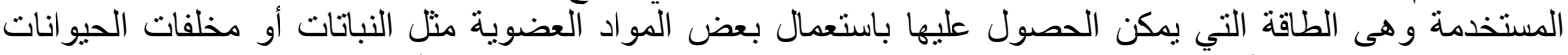

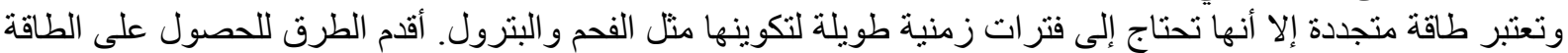

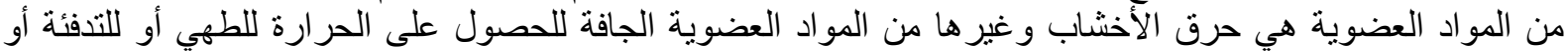

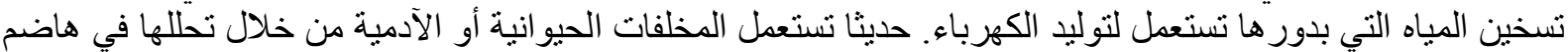

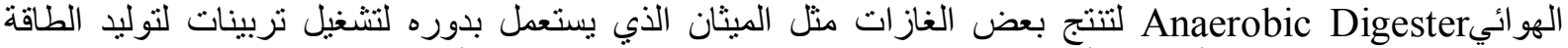

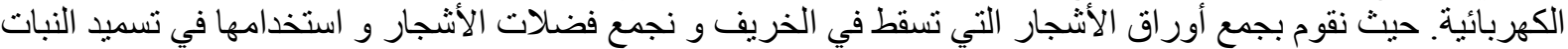

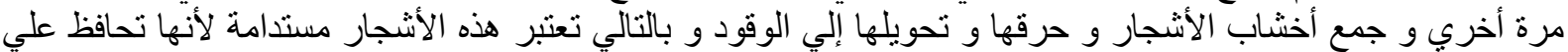

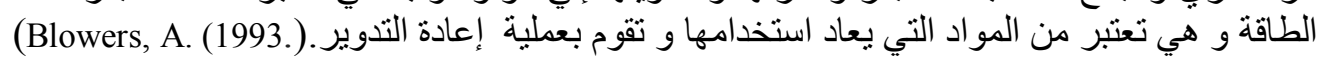




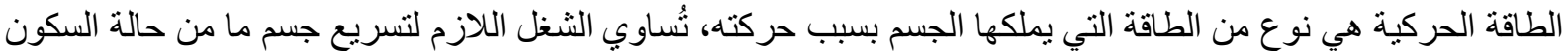

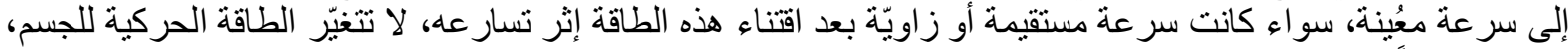

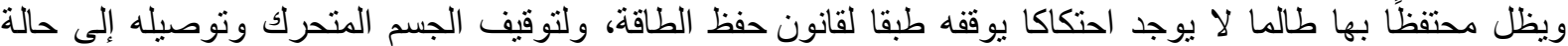

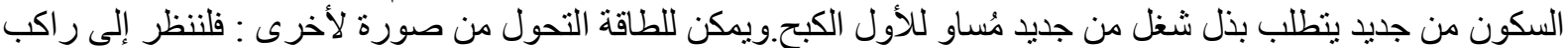

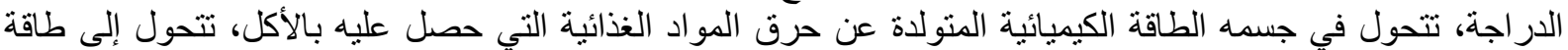

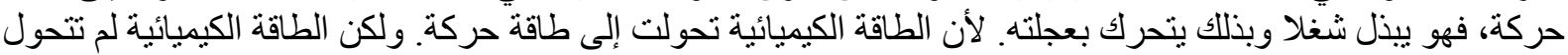

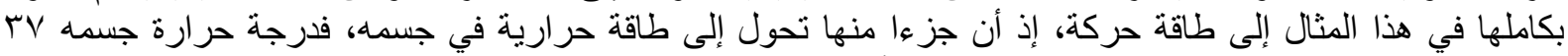

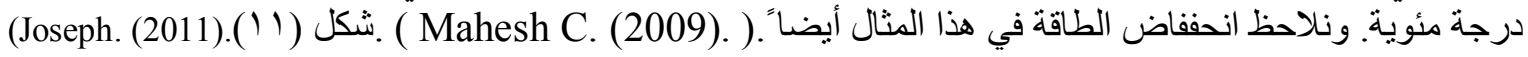
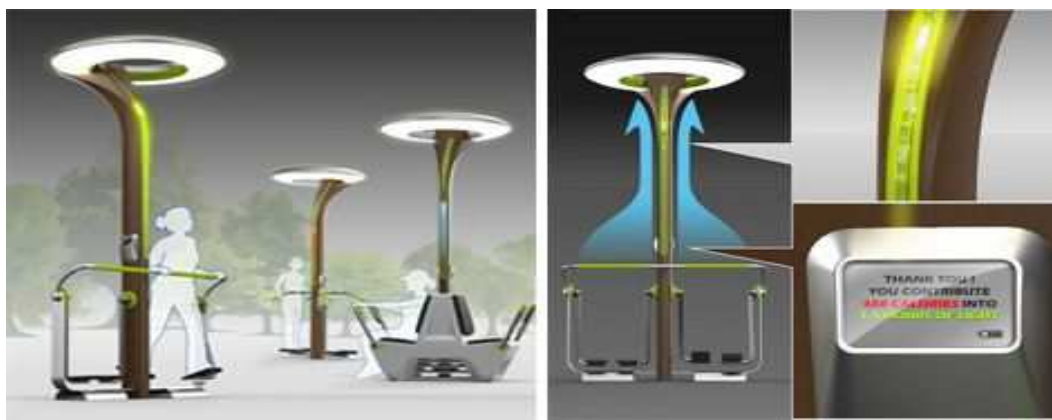

شكل (1 1 ) شكل يوضح توليد طاقة كهربائية عن طريق الارجوحة المضاعة في شارع في مدينة كندا

http://www.techtudo.com.br/curiosidamaquinas

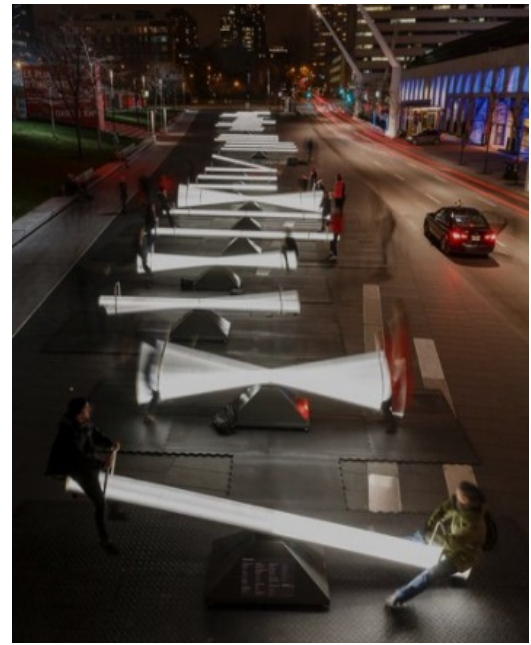

تانيا: استخدام الاجهزة الأكية

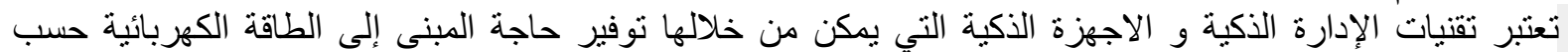

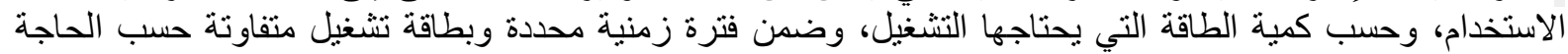

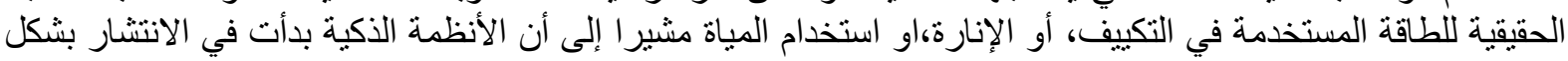

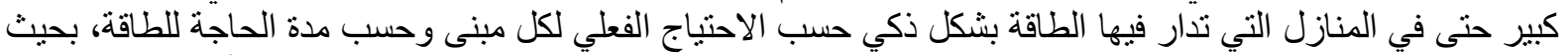

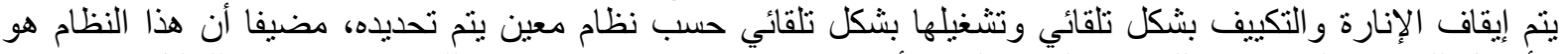
الأفضل للمر افق الحكومية وللمر افق العامة التي بدأ كثبر منها باستخدام طرق حديثة للتحكم في الإنارة للتقليل من كمبات

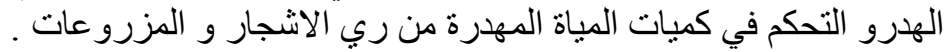
اعمدة الانارة

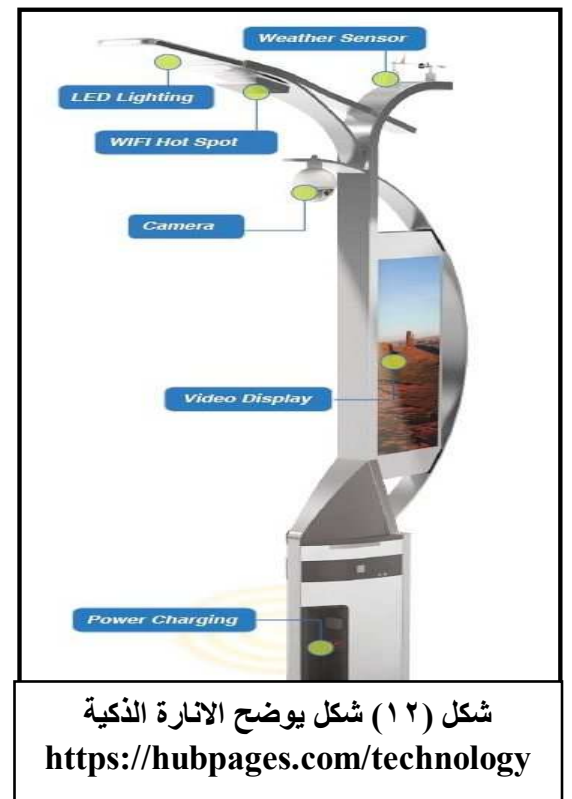
طبق عدد من أمانات المناطق تصاميم هندسية نتناسب مع سياسة الترشيد

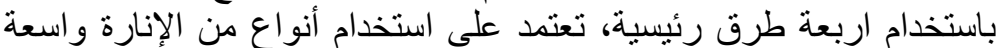

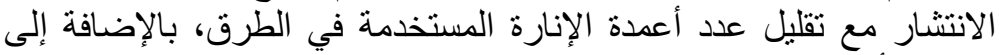

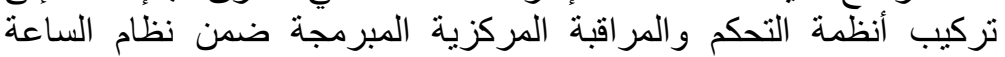

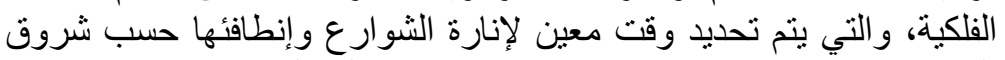

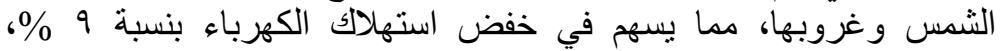

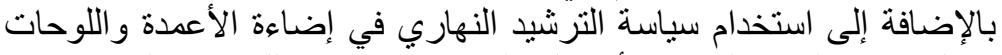

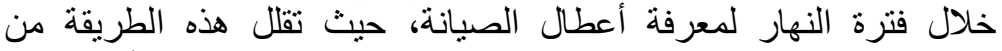

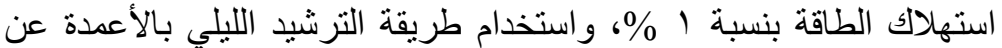

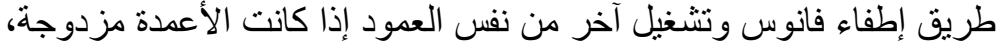

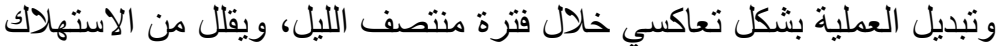

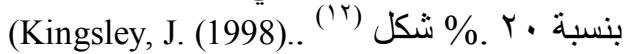




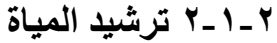

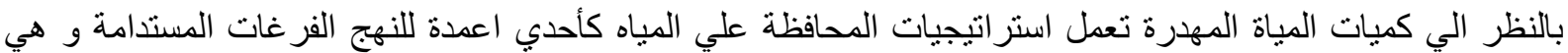

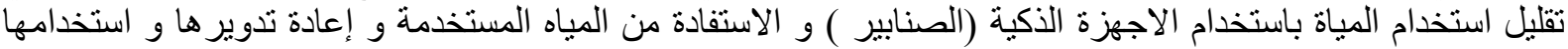

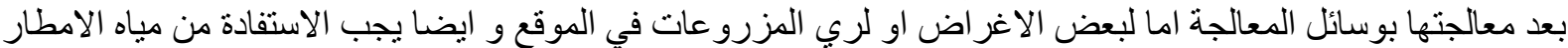

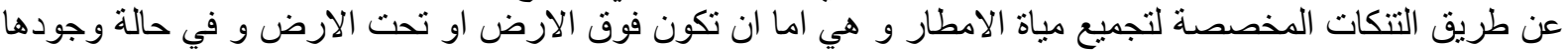

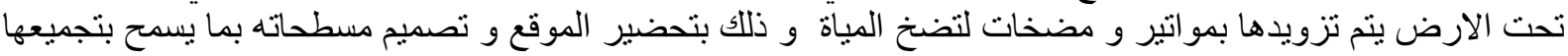

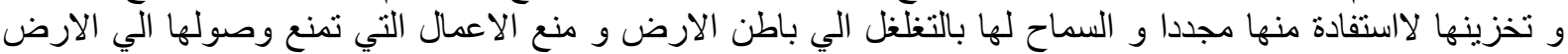

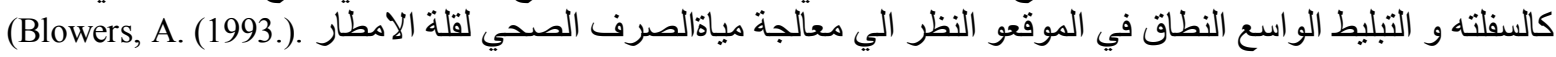

أ ـ ألاستفادة من مياة الامطار

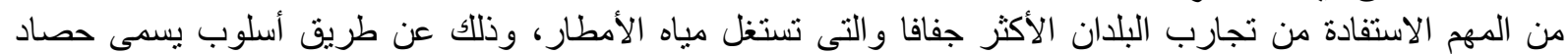

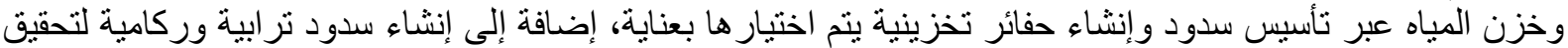

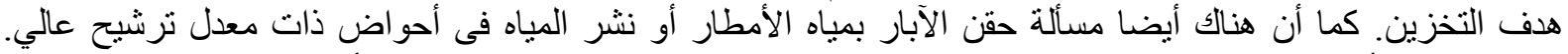

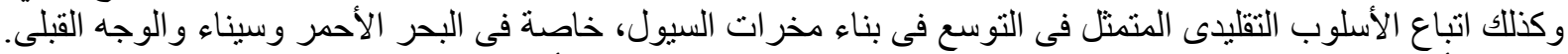

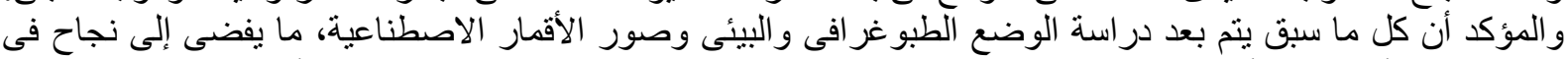

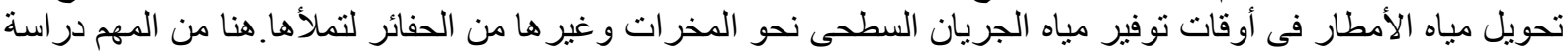

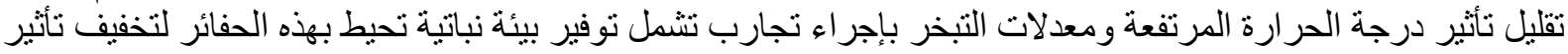

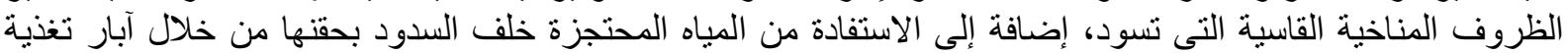

اصطناعية تحفر فى بحيرة السد.شكل (ri')
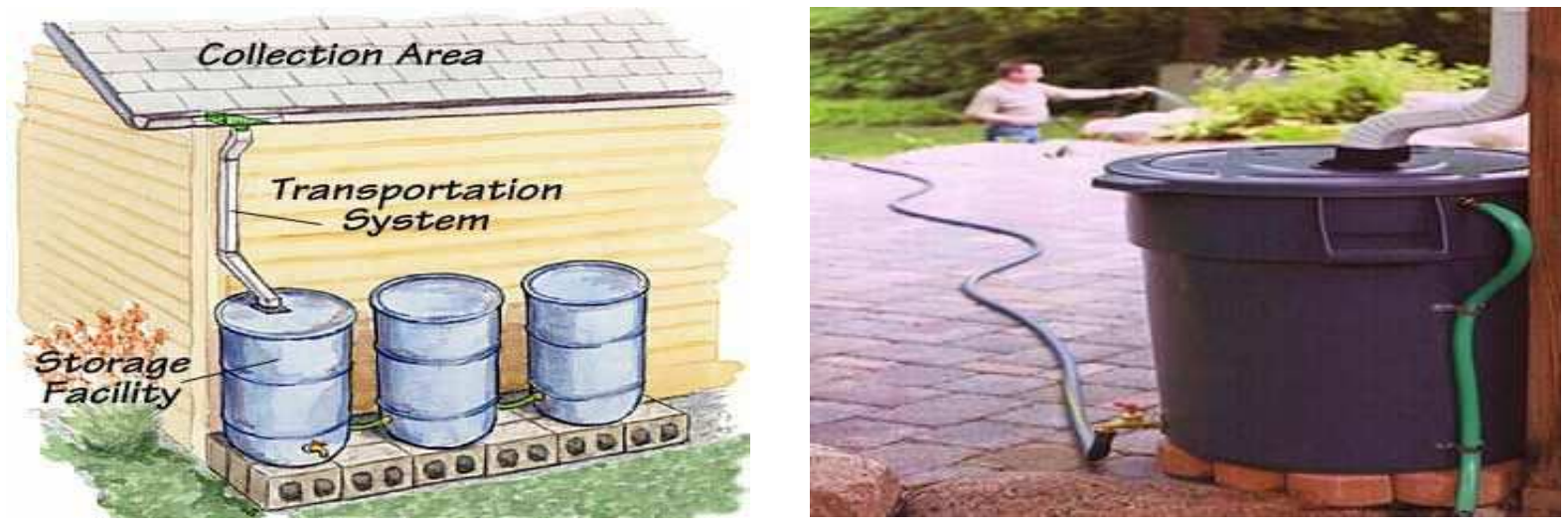

\section{شكل (r I ) شكل يوضح الاستفادة من مياة الامطارلري المزروعات http://www.yourhome.gov.au/water/rainwater}

ب التحكم في ري الحدائق و تثغيل النافورات

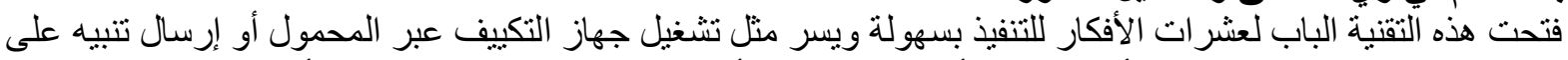

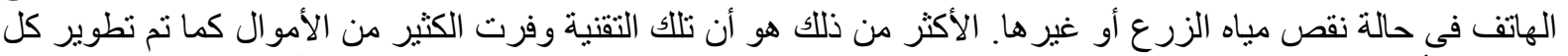

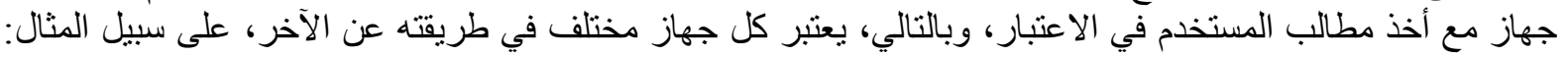

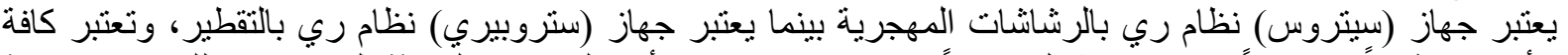

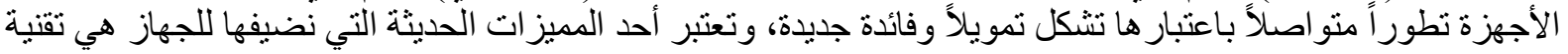

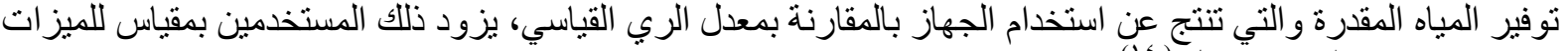

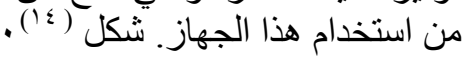

ج- استعمال المياه الرمادية المناه

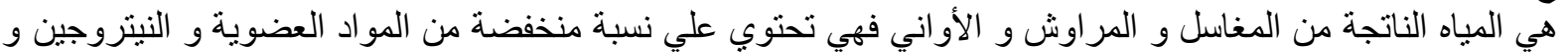

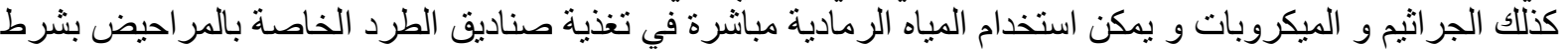

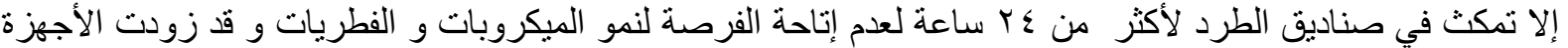

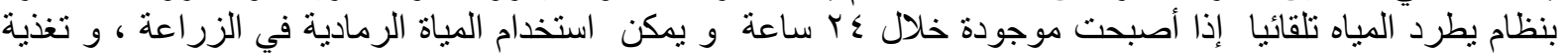
صناديق الطرد الخاصة بالمر احيض عبر محطات تنقية خاصة ـ و يتطلب ذللك ان يكون هناك شبكتان : شبكة مجاري 
لتصريف المباة الرمادية ـ و شبكة اخري للمباة السوداء ـ و تتصل شبكة المياة الرمادية بمحطة تتقبة يختلف تعقبدها تبعا

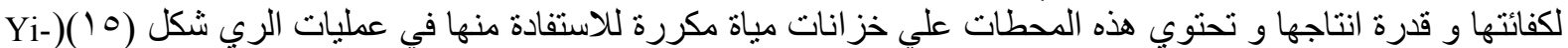

(Kai, J. (2016).

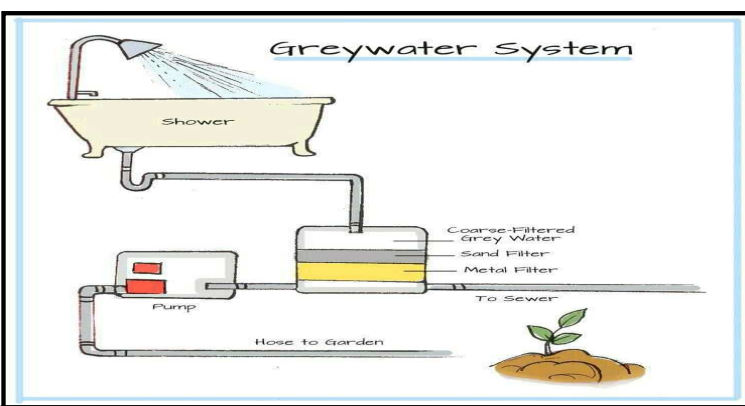

شكل (0 ا 1 ) شكل يوضح استعمال المياة الرمادية http://www.greeneducationfoundation.org/gre en-building-program

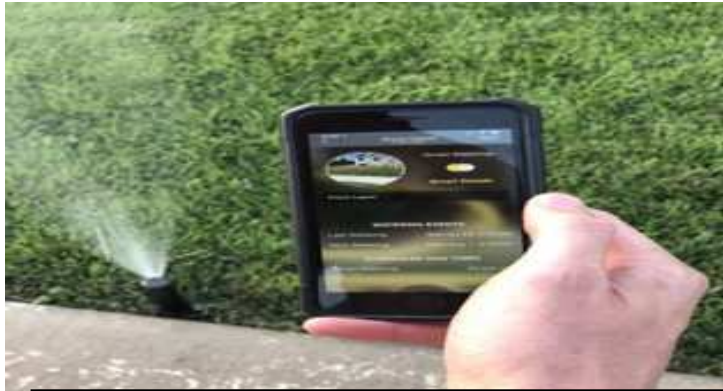

شكل (ء 1 ) شكل يوضح التحكم في ري المزروعات http://www.preventionweb.net/publications

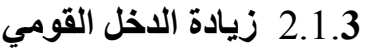

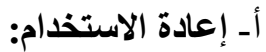

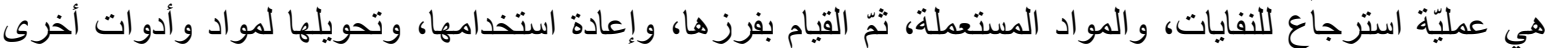

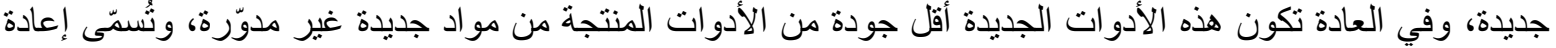

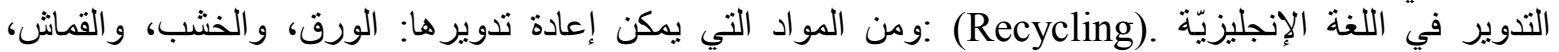

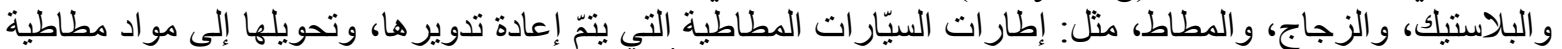

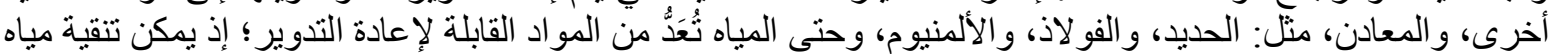

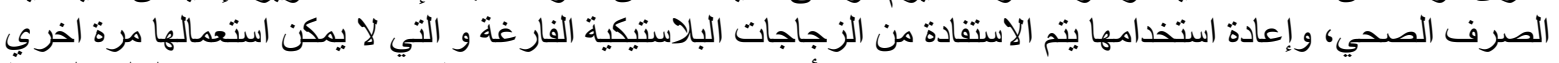

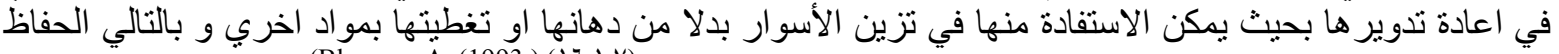

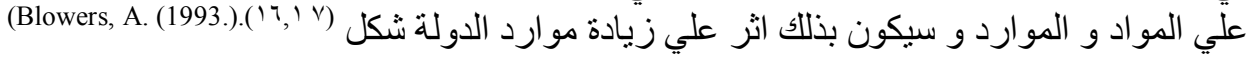
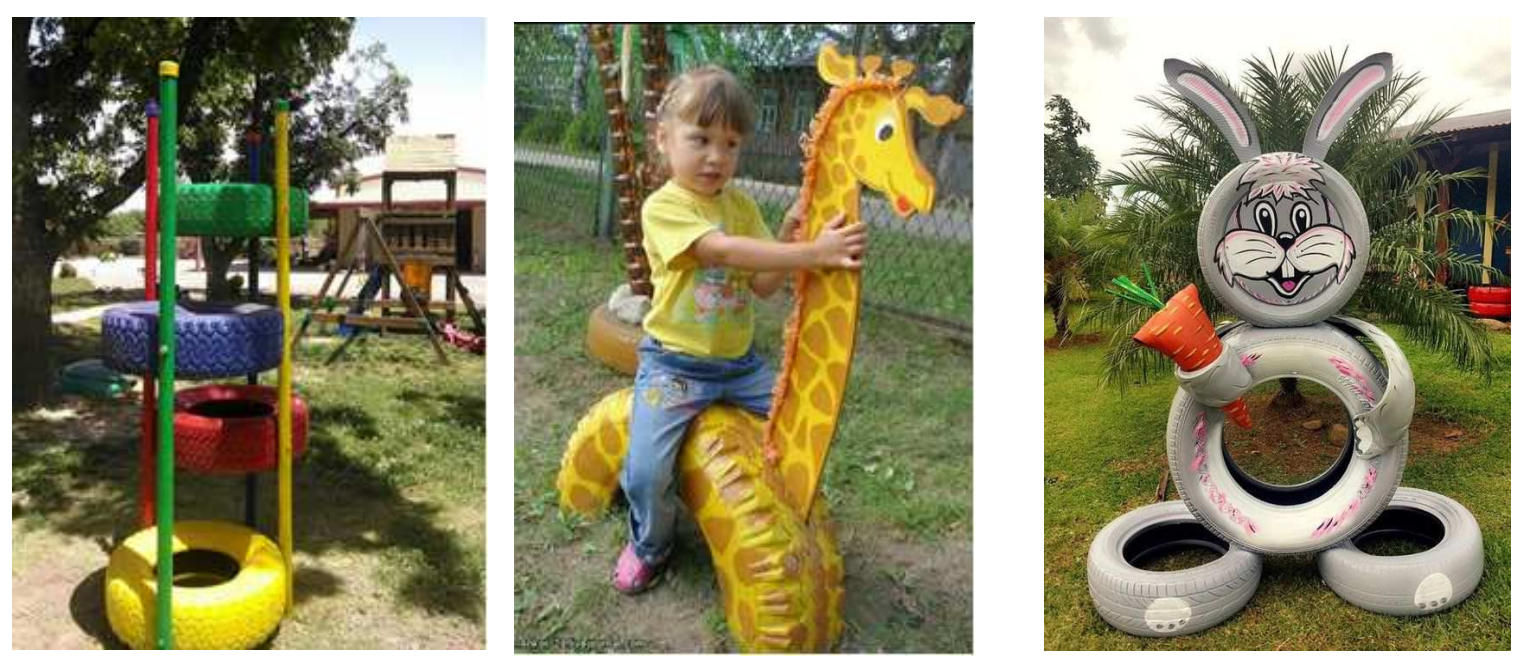

\section{شكل (7 1 ) يوضح كيفية استخدام اطارات السيارات القديمة في مثل مناطق لعب الاطفال و عمل التماثيل المبهجة http://buzz16.com/ways-to-use-old-tires}



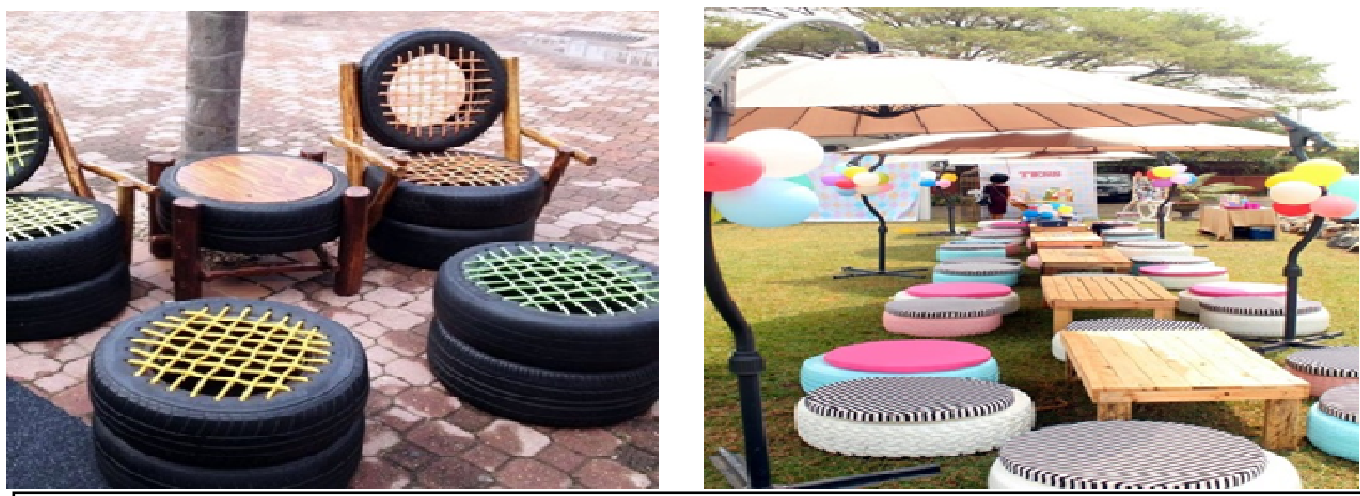

شكل (V V يوضح الطرق المتبعة لاعادة تدوير اطارات السيارات القديمة و استخد/مها في اماكن الجلوس http://www.casinhaarrumada.com

جدول ( 1 ) يوضح تداخل عناصر تنسيق الموقع مع الاستدامة الاقتصادية المصدر : الباحثة

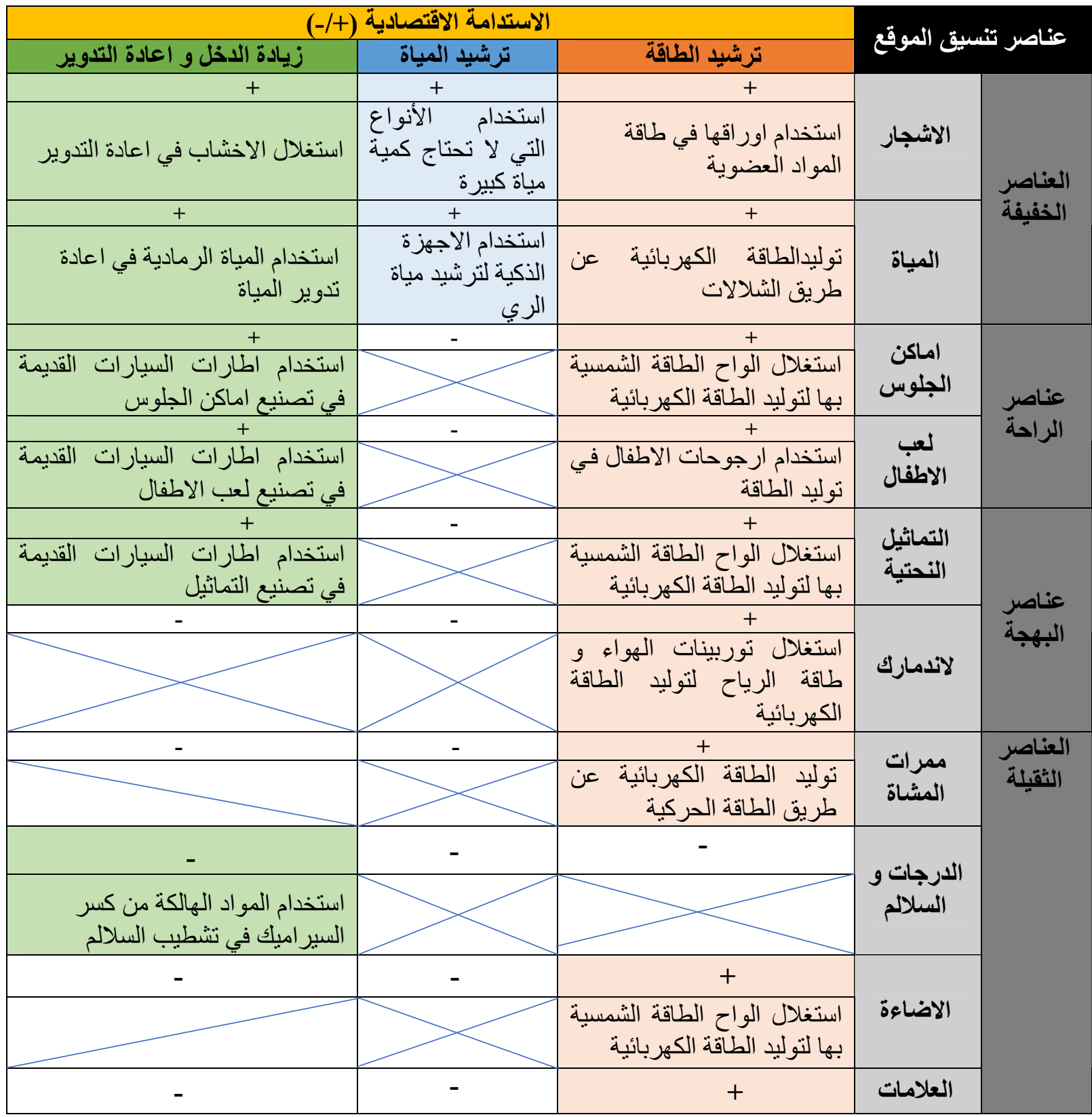


تطوير عناصر تتسيق الموقع لتحقيق الاستدامة الاقتصادية

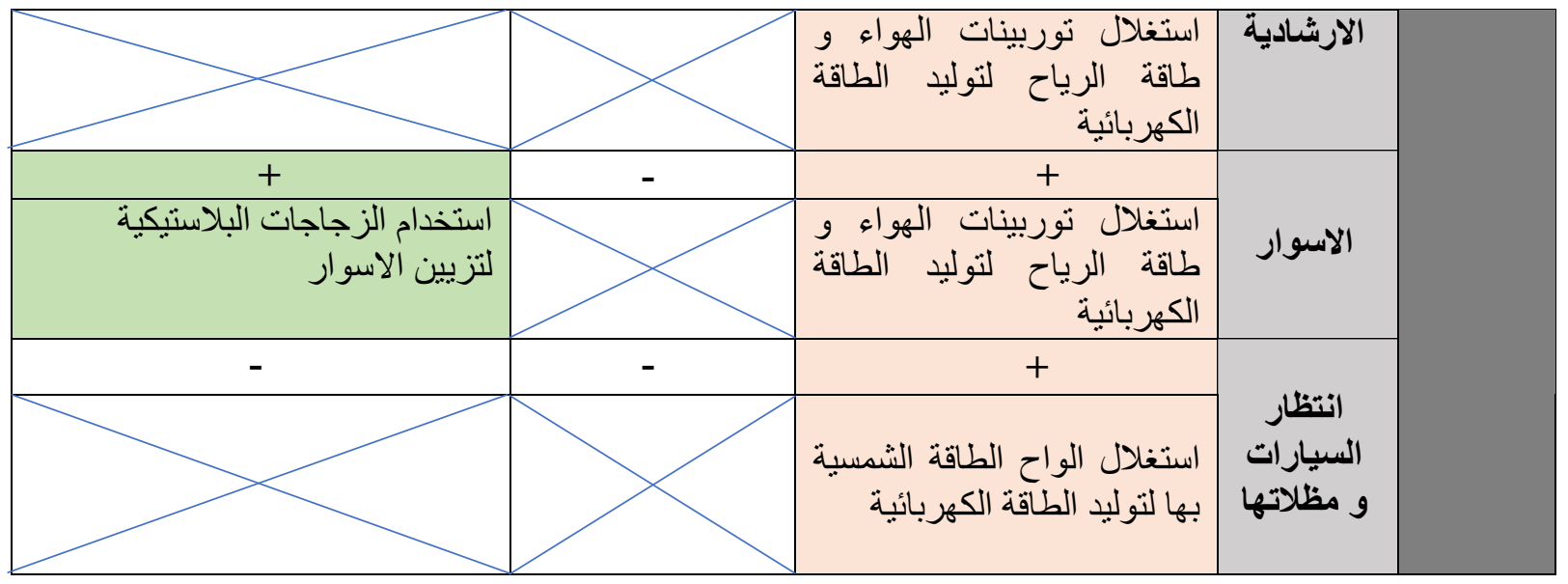

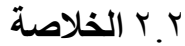

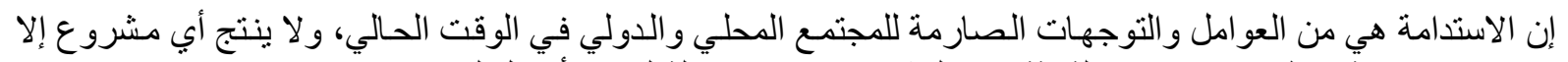

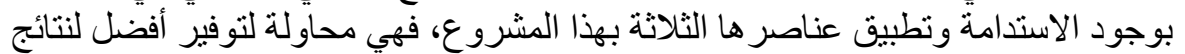

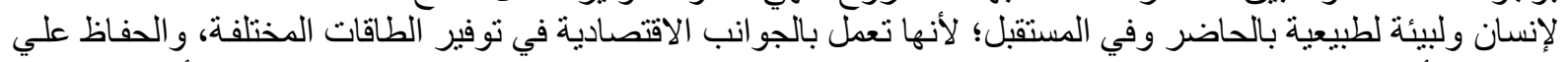

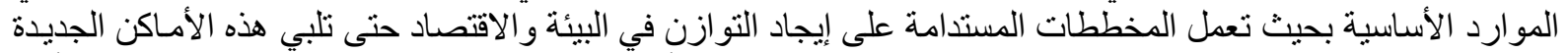

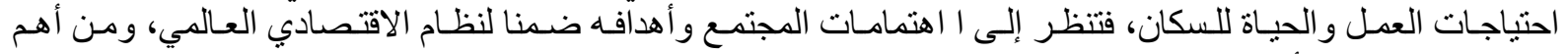

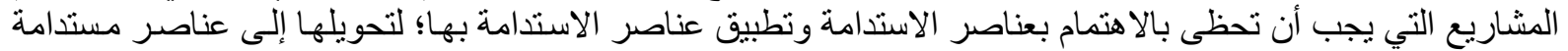
نافعة وغير ضارة بالبيئة هي عناصر تنسيق الموقع بمفرداتها.فتم تطبيق الاستدامة الاقتصادية علي عناصر تنسيق الإنيق الموقع التي تدخل ضمن العند العنصر الاقتصادي.

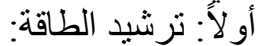

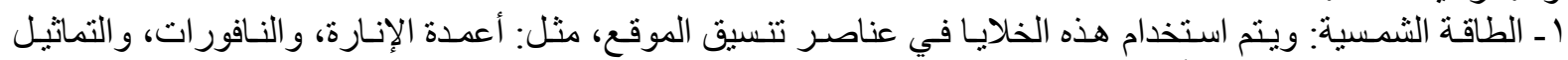
النحتية، ومو اقف السيار ات، وأماكن الجلوس.

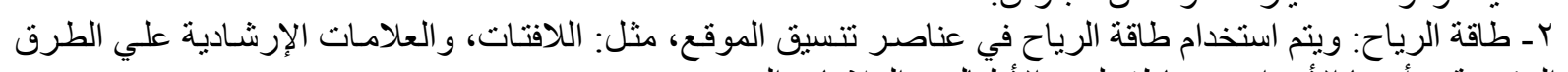

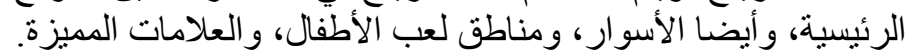

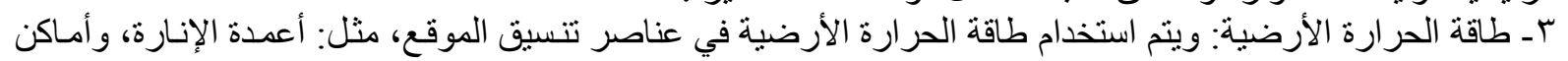

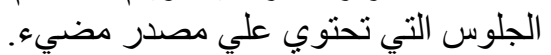

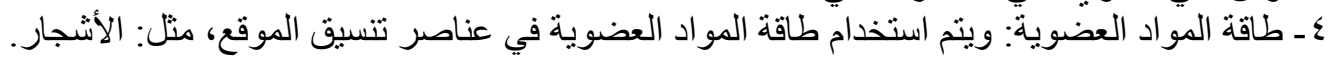

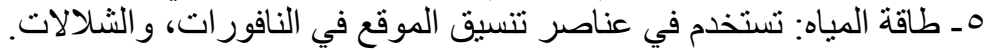

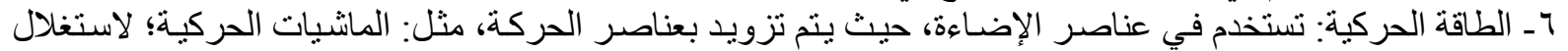

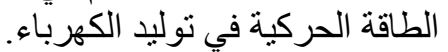
ثانيا : ترشيد المياه: ت النياه

ا ـ الاستفادة من مياه الأمطار : يتم تجميع و الاستفادة من مياه الأمطار لري الحدائق العامة، وزر اعة الأرصفة في الشوارع

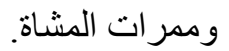
بـ الأجهزة الذكية: ويتم استخدام الاستفادة مـن الأجهزة الذكيـة في عناصـر تنسيق الموقع، مثل: أعمدة الإنـارة، وري

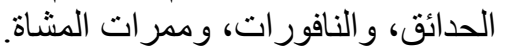

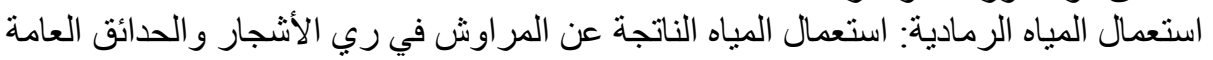

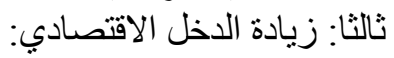

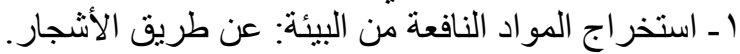

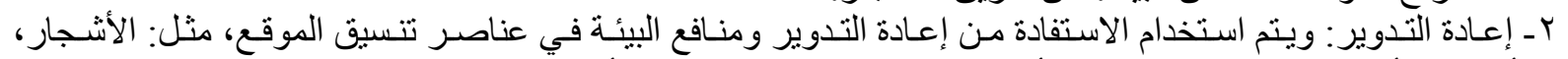
و الأسو إع، وأماكن الجلوس، والتماثثل، وأحو اض الزهن هور، ومناطق لعب الأطفال. 
1. Barton, H. a. (1995). "Sustainable Settlements". England : University of the west of England .

2. Blowers, A. (1993.). "Planning for A Sustainable Environment”. London: . Earthscan.

3. F. Brush. (2000). A Wind Energy Pioneer..

4. Johnson, J. R. (1993). "Heat Flow from the Earth's Interior: Analysis of the Global Data Set" .

5. Joseph. (2011). Advancing Sustainable Materials Management. canada.

6. kiistian. (2011). Renewables 2011 Global Status Report.

7. Kingsley, J. (1998). "Sustainable Cities". United Kingdom.

8. Mahesh, J. (2009). Textbook of Engineering Physics (Part I).

9. Vittrup, C. (2014). "2013 was a record-setting year for Danish wind power. london.

10. Yi-Kai, J. (2016). "Greywater Reuse System Design and Economic Analysis for Residential Buildings in Taiwan". taiwan.

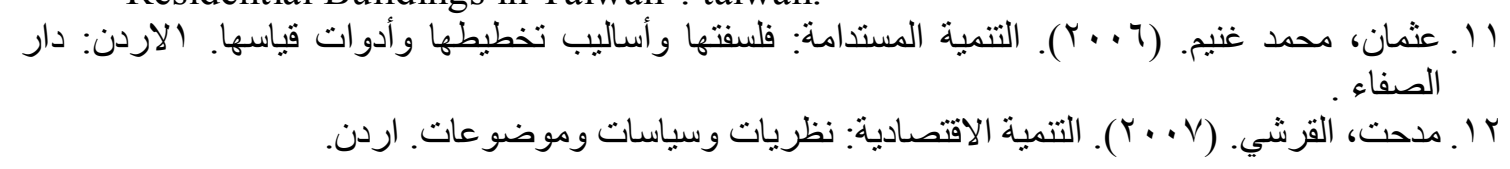

